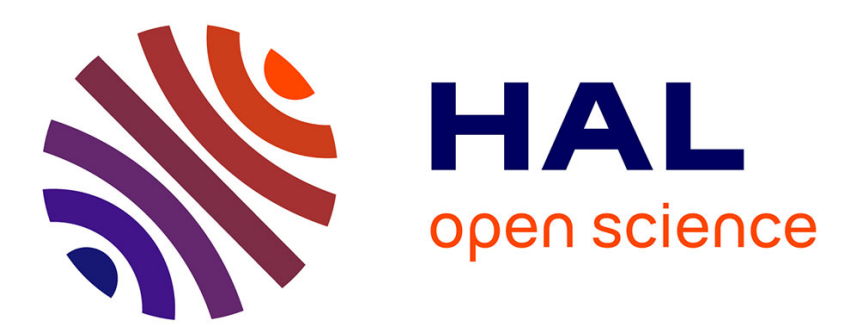

\title{
A Method to Determine the Macroscopic Toughness Scatter of Brittle Materials
}

\author{
Pascal Forquin, Laurent Rota, Yann Charles, François Hild
}

\section{To cite this version:}

Pascal Forquin, Laurent Rota, Yann Charles, François Hild. A Method to Determine the Macroscopic Toughness Scatter of Brittle Materials. International Journal of Fracture, 2004, 125, pp.171-187. 10.1023/B:FRAC.0000021076.76987.62 . hal-00002912

\section{HAL Id: hal-00002912 https://hal.science/hal-00002912}

Submitted on 20 Sep 2004

HAL is a multi-disciplinary open access archive for the deposit and dissemination of scientific research documents, whether they are published or not. The documents may come from teaching and research institutions in France or abroad, or from public or private research centers.
L'archive ouverte pluridisciplinaire HAL, est destinée au dépôt et à la diffusion de documents scientifiques de niveau recherche, publiés ou non, émanant des établissements d'enseignement et de recherche français ou étrangers, des laboratoires publics ou privés. 


\title{
A Method to Determine the Macroscopic Toughness Scatter of Brittle Materials
}

\author{
Pascal Forquin and Laurent Rota
}

DGA/CTA-Département MSP

16 bis avenue Prieur de la Côte d'Or, F-94114 Arcueil Cedex, France.

(pforquin, lrotadetca.fr)

Yann Charles and François Hild*

LMT-Cachan

ENS de Cachan / CNRS-UMR 8535 / Université Paris 6

61 avenue du Président Wilson, F-94235 Cachan Cedex, France.

(hildelmt.ens-cachan.fr)

\begin{abstract}
An experimental procedure is developed to determine the scatter of the macroscopic toughness of brittle materials. First, samples are precracked to obtain a sharp precrack. The toughness is then determined by using a standard three-point flexural test. Digital image correlation is used to analyze displacement fields of cracked samples. Based upon the resolution and the spatial resolution of the measurement technique, a detection criterion is proposed and validated. It allows for an accurate estimate of the crack tip location so that the presence of a crack and its size at arrest can be monitored. As an example, the toughness distribution of 18 samples made of silicon carbide is evaluated. By using a simple macro-micro transition, an analysis of the scatter in toughness is related to that in strength for the material with no macrocracks.
\end{abstract}

Keywords: Crack opening displacement, Digital image correlation, Probabilities and statistics, Sandwiched-beam technique, SiC ceramic, Single-edge notched beam

Abbreviations: COD - Crack opening displacement; DIC - Digital image correlation; SB Sandwiched-beam; SENB - Single-edge notched beam; SiC - Silicon carbide

(C) 2003 Kluwer Academic Publishers. Printed in the Netherlands. 


\section{Introduction}

Fracture toughness is used extensively to design fracture-safe structures. Test methods that measure fracture toughness of materials are necessary for reliable design and accurate failure analysis. For brittle materials, different techniques can be used $[1,2]$. One key aspect is related to the creation of a sharp (pre)crack in the material. Various procedures use notches made by a diamond saw, cracks propagating from prenotches or indentation cracks for ceramics $[3-5,2]$. For example, the SENB (i.e., single-edge notched beam) technique uses prenotched beams and the toughness associated with a notch may differ from that of a sharp crack [6].

To evaluate the fracture toughness of a brittle material (e.g., a silicon carbide ceramic), a sandwiched-beam precracking technique may be used [79]. This type of experimental set-up allows one to initiate a crack that does not propagate across the whole sample. However, the arrest conditions are strongly dependent upon the friction between the beams, their flexural rigidities, the notch geometry as well as the variations of material properties around the notch. Furthermore, it will be shown that the load displacement curve has no precise signature corresponding to the onset of crack propagation. To control precracking of the tested beam, it is proposed to monitor the precrack size by using a displacement field measured by digital image correlation.

Vision-based techniques have been utilized to analyze cracks in homogeneous and heterogeneous materials [10]. For instance, crack tip opening angles [11] or crack tip opening displacements [12] can be measured with a very good accuracy by means of digital image correlation. In most of the

\footnotetext{
${ }^{*}$ to whom correspondence should be addressed. Fax: +33147402240.
} 
experiments reported, a random pattern was sprayed and the crack was visible on the pictures. In the present case, no surface preparation is used and the crack is not visible. Consequently, there is a need to devise a detection criterion that can be used during a precracking experiment and only be checked a posteriori on a fractured surface. To achieve a good spatial resolution, a far-field (or long-distance) microscope is used to get access to the onset and arrest of crack propagation from a notch.

Section 2 introduces the experimental procedure used to measure the toughness of brittle materials. A sandwiched-beam technique is first used to precrack a notched beam. It is followed by a three-point flexural test on the precracked sample to determine the toughness of the tested specimen. The previous procedure is applied to a silicon carbide ceramic in Section 3. To determine the onset of cracking, a Digital Image Correlation (DIC) technique is used to measure the displacement field. It is shown that, in the present case, it is the only reliable way. A criterion for the location of the crack tip is proposed and validated in a 'blind' configuration for which no other way exists to locate the crack tip. In Section 4, the scatter of the macroscopic toughness is determined by means of a Weibull distribution. By using a simple macromicro transition, it is shown that classical Weibull parameters related to the variation of strength can be related to toughness variations as well as flaw size distributions within the material. 


\section{Experimental Procedure}

To analyze the toughness scatter, the proposed experimental procedure is divided into two parts. First, a notched sample is precracked by using a sandwichedbeam technique. To monitor the crack tip, the displacement field is determined by using a digital image correlation technique. Second, the precracked sample is subjected to a three-point flexural test to evaluate the toughness. By repeating the experiments and by carefully minimizing the experimental uncertainties, an analysis of the toughness scatter can be performed.

\subsection{SANDWICHED-BEAM TEChNIQUe FOR PRECRACKING}

The principle of an SB test consists in inserting a notched bar $(N)$ between two steel bars ( $A$ and $B$, see Fig. 1-a). The sandwich assembly is then loaded in three-point flexure. If $P$ denotes the applied load and $L$ the outer span, the moment $M_{N}$ in the notched beam is expressed as

$$
M_{N}=\frac{P L}{4} \frac{(E I)_{N}}{(E I)_{A}+(E I)_{N}+(E I)_{B}},
$$

where $(E I)_{A},(E I)_{N},(E I)_{B}$ are the flexural rigidities of the three beams, $E$ the Young's modulus and $I$ the moment of inertia. By using this approach, the notched beam $N$ can be considered as being loaded in three-point flexure by an apparent load $P_{N}$

$$
P_{N}=P \frac{(E I)_{N}}{(E I)_{A}+(E I)_{N}+(E I)_{B}},
$$

so that the stress intensity factor can be evaluated as

$$
K=\frac{P_{N} L}{b_{N} w_{N}^{3 / 2}} \eta\left(\alpha, L / w_{N}\right)
$$


where the function $\eta$ depends on the normalized crack size $\alpha=a / w_{N}$ and span $L / w_{N}$ [13], $w_{N}$ is the height of the notched beam and $b_{N}$ the corresponding width (Fig. 1-a). Figure 1-b shows an example of the stress field obtained by FE simulations. The average stress field $\bar{\sigma}_{i j}(i, j=1,3)$ in the beams is defined by

$$
\bar{\sigma}_{i j}(x, y)=\frac{1}{b} \int_{-b / 2}^{b / 2} \sigma_{i j}(x, y, z) \mathrm{d} z .
$$

The stress $\bar{\sigma}_{11}$ is very close to that observed in three-point flexure. The average stress field $\bar{\sigma}_{22}$ shows that contact is likely to occur over the whole surface even though the Young's modulus of the notched bar is greater than that of the two outer beams.

From the FE computations, one can determine the stress intensity factor. The mesh used was first validated on a precracked beam for which a wellknown expression exists for the stress intensity factor [13]. Numerically, the latter is evaluated by using the $J$-integral or the square-root dependence of the displacement field. Both methods yield errors less than $2 \%$ when compared to Eqn. (3). The same numerical techniques are used in the SB configuration. Figure 2 shows the change of the stress intensity factor $K$ with the normalized crack size $\alpha=a / w_{N}$ for two values of the ratio $r_{0}$ defined by [2]

$$
r_{0}=\frac{(E I)_{A}+(E I)_{B}}{(E I)_{N 0}}
$$

where $(E I)_{N 0}$ denotes the flexural rigidity of the unnotched sample. When $r_{0}=6.3$ (i.e., $b_{A}=b_{B}=9 \mathrm{~mm}, b_{N}=3 \mathrm{~mm}, w_{A}=5.5 \mathrm{~mm}, w_{B}=7 \mathrm{~mm}$, $w_{N}=5 \mathrm{~mm}, E_{A}=E_{B}=210 \mathrm{GPa}, E_{N}=410 \mathrm{GPa}$ ), the result is compared with FE simulations in which different friction coefficients of the contact surfaces between the beams are considered. With frictionless surfaces, the two calculations are close. However, when the friction coefficient of the surfaces 
increases, the stress intensity factor decreases. This is caused by a decrease of the crack mouth opening displacement in the notched specimen. These results show that if one assumes a constant toughness, stable crack growth can occur since there exists a range of negative values of the derivative of $K$ with respect to $\alpha$ (when $\alpha>\alpha^{*}$ ). Furthermore, Fig. 2 shows that depending on the friction coefficient, which is generally not well known, the generated precrack size can be different since $\alpha^{*}$ depends on $f$ and $r_{0}$. These computations prove that the evaluation of the stress intensity factor of the precrack is not an easy task when the location of its tip is not known precisely. Last, in the following application, a value of $\alpha=0.4 \pm 0.05$ is chosen for the notch so that cracking is likely to be stable from the onset on ( $\alpha^{*} \approx 0.3$, see Fig. 2$)$.

Figure 3 shows the experimental set-up used to precrack ceramic samples. Three steps are needed to prepare a precracking experiment. First, the support arm is inserted between the support and loading systems. The loading system is moved downwards to touch the support arm. The latter is centered with respect to the loading system thanks to a V-shaped groove. The support system is aligned with respect to the support arm by an index. Second, the three beams are put between the loading and support systems, and one of their surfaces is in contact with the support arm so that their mid-plane coincides. Third, two sliding blocks are used to move the three beams along the support arm. An aperture in the support arm, through which beams of light traverse, allows one to bring the notch mi-plane in coincidence with the axis of the loading system. An uncertainty less than $\pm 30 \mu \mathrm{m}$ is achieved.

The load level is increased by steps of $200 \mathrm{~N}$ up to $1000 \mathrm{~N}$, then by smaller steps of $50 \mathrm{~N}$. Thanks to the hole drilled in the support arm, a longdistance microscope is used to observe a small zone around the notch to 
detect the onset of cracking. By acquiring pictures at each load level and using a charge-coupled device (CCD) camera, it is possible to determine the in-plane displacement field by matching different zones of two pictures [12]. The simplest image-matching procedure is cross-correlation, which can be performed either in the physical space $[14,15]$ or in Fourier space [16-18]. It consists in looking for the maximum correlation between small zones in the 'deformed' and reference images. The translation, which corresponds to the maximum correlation, can thus be extracted for different positions of the zone of interest. The extensive use of Fast Fourier Transforms (FFT) is very effective in reducing the computation cost. For 8-bit images, sub-pixel resolution can be achieved and values as low as a few hundredth of one pixel are found by using the CORRELI ${ }^{\mathrm{LMT}}$ software $[19,20]$.

\subsection{Three-Point Flexure for Toughness Measurements}

Once the sample is precracked, the experiment is stopped. The two beams are removed and the sample is repositioned in the setup by following the same procedure as before. By knowing the crack size $a$ (by optical microscopy of the fractured surface) and the maximum load level $P_{c}$ (recorded during the experiment), one can determine the corresponding toughness $K_{c}$

$$
K_{c}=\frac{P_{c} L}{b_{N} w_{N}^{3 / 2}} \eta\left(\alpha, L / w_{N}\right) .
$$

If this type of procedure is repeated, one can study the scatter in toughness. It is believed that the numerous experimental precautions enable us to minimize the scatter related to all the handling of the sample and more specifically the position of its axis with respect to that of the testing machine. It can be noted that this type of procedure is applicable to any brittle material, pro- 
vided the size of the sample is consistent with that of the underlying material microstructure.

\section{Application to a Silicon Carbide Ceramic}

The previous experimental procedure is now used to analyze the toughness scatter of silicon carbide samples.

\subsection{STUdied MATERIAL}

The material examined herein, called $\mathrm{SiC}-100$ and made by Céramiques \& Composites (France), is naturally sintered. The powder is pressed and then heated to $2000^{\circ} \mathrm{C}$. During processing, small quantities of boron carbide $\left(\mathrm{B}_{4} \mathrm{C}\right)$ are added to improve sintering. The porosity was evaluated by Riou [21] and is of the order of $1.8 \%$. The average grain size is equal to $5 \mu \mathrm{m}$. The microstructure of the ceramic also induces important consequences regarding 3-point flexural tests. The behavior of ceramics under 'tensile' loading is elastic, brittle and scattered in terms of ultimate failure load. Flaws initiating failure were identified. These flaws are found by following hackles generated by transgranular fracture and by looking for the mirror zone that surrounds the flaw. The flaws generally observed are sintering defects (Fig. 4), the size of which can be sub-micrometric and as high as a few tens of micrometers.

The typical size of the microstructure is micrometric. Therefore, when artificial cracks are at least of millimetric size, a macroscopic evaluation of the stress intensity factor can be performed. The results derived in Section 2 
can be used. The measurements performed herein correspond to macroscopic evaluations of the toughness and its scatter.

\subsection{Detection of the Crack Tip Location by DiC}

One way of determining the onset of propagation is to monitor the load level as a function of the loading parameter (e.g., the crosshead displacement or time). Figure 5-a shows the change of load with time for a monotonic crosshead displacement of $10 \mu \mathrm{m} / \mathrm{min}$ during the precracking experiment. Only a very small load drop (i.e., $2 \mathrm{~N}$ to compare to a level of more than $1000 \mathrm{~N}$ ) can be observed. This drop is comparable to the measurement fluctuations (see zoom of Figure 5-a). Consequently, this technique is not reliable enough to detect the onset of crack propagation.

An alternative route consists in observing one of the lateral surfaces of the beam by using a long-distance microscope (QUESTAR QM100). This is made possible by the hole drilled in the support arm (Fig. 3). The main advantage is that a microscopic resolution can be achieved from a longer distance than conventional microscopes. It allows the user to work at distances of $15 \mathrm{~cm}$ to $35 \mathrm{~cm}$ from the surface of interest. Values as small as $1.1 \mu \mathrm{m}$ separation can be resolved at $15 \mathrm{~cm}$ from the surface. This type of technique was successfully used to detect the crack tip in a 2024-T3 aluminum alloy with an artificial pattern [11, 12]. A brightfield illumination is used in the present case and no special sample preparation is needed. At these magnification levels, the surface roughness provides enough variations so that speckles appear. Figure 5-b shows a picture taken when the load drop was observed. No crack is visible even with the highest magnification. 
Figure 6 shows the displacement fields obtained for the same load level (i.e., $P=1050 \mathrm{~N}$ ). By using the contours of the displacement $u_{1}$, the crack opening (i.e., the displacement discontinuity) can be seen clearly. In particular, it can be stated that the onset of crack propagation occurred prior to the load level $P=1050 \mathrm{~N}$. The analysis of an image taken when $P=1010 \mathrm{~N}$ does not show any discontinuity. By using the present observations, the onset of crack propagation occurred for a load level greater than $1010 \mathrm{~N}$ and less than 1050 N. It can also be concluded that the load drop observed in Fig. 5-a is probably related to the same event.

\subsection{Detection CRiterion}

The location of the crack tip requires the user to choose a detection criterion. This is not an easy task since the displacement contours depend on the magnitude of the displacement. Figure 7 shows $u_{1}$-displacement contours using two different displacement ranges for the same average displacement.

The first step of the analysis consists in evaluating the resolution of the DIC technique. This is performed by using the reference picture of the experiment and prescribing artificially a sub-pixel displacement, here in the (horizontal) 1-direction since the crack is oriented preferentially along the (vertical) 2-direction. A linear interpolation is used to evaluate the pixel graylevel of the perturbed case. Figure 8 compares the displacement evaluations for different sizes of the interrogation window. The shift between two neighboring centers is identical to the length of a window so that there is no overlapping. The higher the window size, the more accurate the displacement evaluation. However, the displacement field is less resolved spatially. In the present case, 
a good compromise is given by a size equal to $32 \times 32$ pixels for which an RMS resolution less than 0.045 pixel is obtained (a $64 \times 64$ pixel ZOI has an RMS resolution less than 0.033 pixel). A shift between two consecutive ZOIs equal to 16 pixels is chosen. Based upon the previous study, a displacement range is set at 0.1 pixel, which is a good compromise between the displacement resolution and the spatial location of the crack tip. With the use of a long-distance microscope, 1 pixel corresponds to $1.85 \mu \mathrm{m}$ and a crack opening of the order of $80 \mathrm{~nm}$ can be measured with a good accuracy.

Figure 9-a shows that the contours of the displacements perpendicular to the crack face are horizontal when the crack tip is above the considered line. This is confirmed by FE computations shown in Fig. 9-b. Consequently, it is proposed to detect the crack tip by looking at the contours of $u_{1}$-displacements and finding the point where they are no longer parallel to the 1-direction. To detect a crack (i.e., a discontinuity in the displacement field), the minimum distance between two measurement points has to be equal to the size of the ZOI (e.g., 32 pixels) so that no overlapping occurs augmented by one shift (e.g., 16 pixels) between two neighboring centers to avoid that the crack mouths are within the considered ZOIs. In terms of crack tip location, let us use the classical plane stress solution expressing the near tip displacement field when the stress intensity factor is equal to the toughness $K_{c}$. Under these assumptions, the displacement discontinuity $\delta_{1}$ in the 1-direction is given by

$$
\delta_{1}=2 u_{1}\left(r=d_{1} / 2, \theta=\pi / 2\right)=\frac{K_{c}}{E_{N}} \sqrt{\frac{d_{1}}{2 \pi}}\left(3-v_{N}\right),
$$

where $d_{1} / 2$ is the minimum horizontal distance of two symmetric points with respect to the crack tip (e.g., $32+16$ pixels or $90 \mu \mathrm{m}$ in the present case), 
$v_{N}$ the Poisson's ratio of the uncracked sample. A value for $\delta_{1}$ equal to 0.04 pixel is found, and corresponds to the point where a first and fifth consecutive contours are still horizontal when a displacement range of 0.1 pixel is chosen and $K=K_{c}$. It can be noted that the latter is compatible with the resolution of the technique. Furthermore, the shift between two consecutive centers corresponds to an upper bound of the uncertainty on the locus of the crack tip along the 2-direction. A value of the order of $30 \mu \mathrm{m}$ (or 16 pixels) is obtained. Therefore, the relevant crack sizes to consider is millimetric (i.e., macroscopic) so that the relative length error $\Delta a / a$ is less than $3 \%$ so that the relative toughness error $\Delta K_{c} / K_{c}$ induced by an error in crack location is less than $1.5 \%$ by using the present technique. This analysis shows that DIC is a viable way of locating a crack when no other means are at hand. The square root dependence of the displacement field [Eqn. (7)] allows for a precise location of the crack tip with a sub-pixel correlation algorithm (Fig. 9).

Following precracking experiments, the samples are loaded in a classical three-point flexural test with the same positioning arm. Contrary to conventional SENB techniques, there exists a sharp precrack. To analyze the robustness of the whole experimental procedure, the displacement corresponding to arrest in a precracking experiment is compared to that obtained subsequently at the onset of crack propagation in the flexural test. Figure 10 compares the two displacement fields. One can note a good reproducibility of the crack location for load levels significantly different (namely, $F=1200 \mathrm{~N}$ in the SB test, and $F=31.1 \mathrm{~N}$ in the subsequent test).

By increasing the displacement range, an evaluation of the COD is carried out. Figure 10 shows the contours allowing for the crack location. From this first analysis, the displacement range is quadrupled (Fig. 11-a) and at a 
distance from the crack tip of the order of $0.6 \mathrm{~mm}$, the measured COD is equal to $0.6 \mu \mathrm{m}$ to compare with a computed value of $0.65 \mu \mathrm{m}$. This result is in agreement with a resolution of the order of $60 \mathrm{~nm}$. The whole COD profile can be evaluated following the same approach. Figure 11-b shows a good agreement between measured and predicted (by FE analyses) CODs. This information can also be used to evaluate the crack tip location and the stress intensity factor. By using the classical expression for the COD $\llbracket u_{1} \rrbracket$ under a plane stress condition,

$$
\llbracket u_{1} \rrbracket=\frac{8 K}{E_{N}} \sqrt{\frac{r}{2 \pi}}
$$

where $r$ is the distance of the current point with respect to the crack tip, a value of $K=2.90 \pm 0.05 \mathrm{MPa} \sqrt{\mathrm{m}}$ is obtained and a position $x_{2}=3.25 \pm 0.01 \mathrm{~mm}$. It can be noted that the position is determined with a similar accuracy as with the previous technique.

Last, when the sample is broken, the analysis of the fractured surface, allows us to fully validate the detection criterion. Figure 12 compares the evaluated crack length at the end of the precracking experiment (i.e., $\left(a-a_{0}\right) / w_{N}=$ 0.186 , where $a$ is the current crack size, and $a_{0}$ is the initial notch size) and that determined from a fractographic observation (i.e., $\left.\left(a-a_{0}\right) / w_{N}=0.191\right)$. There is a small underestimation that is in agreement with the a priori predictions. The detection criterion is considered to be validated and is now used to study the toughness of SiC-100. 


\section{Toughness Scatter of SiC-100}

In the present section, the toughness scatter is analyzed and then related to that observed with a classical Weibull model written in terms of strength.

\subsection{Statistical AnALYSis}

Thanks to all the tests performed in the previous section, it can be stated that the scatter induced by whole experimental procedure is minimal, and if there exists a scatter in toughness values, it is likely to be representative of the material containing sharp millimetric (i.e., macroscopic) cracks. 18 different experiments were performed and the toughness values are put in ascending order so that for the $i$-th value, the cumulative probability $P_{i}$ is expressed as

$$
P_{i}=\frac{i}{N+1},
$$

where $N$ is the total number of experiments. If the cumulative probability $P_{i}$ is modeled by a Weibull law [22], it is convenient to plot the results in a socalled Weibull plot [23] in which the abscissa is the natural logarithm of the toughness and the ordinate is $\ln \left(-\ln \left(1-P_{i}\right)\right)$ so that the slope is the Weibull modulus $n$ and the intercept is the scale parameter $K_{0}$ (Fig. 13) of the best fit $G$

$$
G=1-\exp \left[-\left(\frac{\left\langle K_{\mathrm{c}}\right\rangle}{K_{0}}\right)^{n}\right] .
$$

In the present experiments, the Weibull parameters are $n=24, K_{0}=2.9 \mathrm{MPa} \sqrt{\mathrm{m}}$ and the average toughness $\bar{K}_{c}$ is expressed as

$$
\bar{K}_{c}=K_{0} \Gamma\left(1+\frac{1}{n}\right)=2.85 \mathrm{MPa} \sqrt{\mathrm{m}},
$$


where $\Gamma$ is the Euler (gamma) function of the second kind [24]. The average found here is in good agreement with values reported by Merkel and Messerschmidt [25], and Riou [21]. The corresponding standard deviation $\overline{\bar{K}}_{c}$ is given by

$$
\overline{\bar{K}}_{c}=K_{0} \sqrt{\Gamma\left(1+\frac{2}{n}\right)-\Gamma^{2}\left(1+\frac{1}{n}\right)}=0.15 \mathrm{MPa} \sqrt{\mathrm{m}} .
$$

The coefficient of variation $\overline{\bar{K}}_{c} / \bar{K}_{c}$ is of the order of $5 \%$ so that the onepercent resolution on the toughness measurements is needed in the present case.

\subsection{MACRO-Micro Transition}

In the following, a simple macro-micro transition is performed when considering the toughness distribution. Even though the macroscopic toughness can be the result of weak or strong pinning regimes [26-29], it is assumed, as a first approximation, that the toughness distribution at the scale of the sintering flaws is identical to the one measured for macroscopic cracks. For a brittle ceramic with no macroscopic cracks, its failure is caused by sintering defects (Fig. 4), which are randomly distributed. The latter are modeled as cracks of radius $a$ perpendicular to the local maximum principal stress direction (i.e., the considered equivalent stress $\sigma^{\star}$ is the maximum principal stress). The stress intensity factor $K$ of these microscopic cracks is written as

$$
K=Y \sigma^{\star} \sqrt{a}
$$

where $Y$ is a dimensionless parameter accounting for the approximation of the defect geometry as well as the fact that the grain size (i.e., $5 \mu \mathrm{m})$ is only slightly less than the typical sintering flaw size (i.e., $15 \mu \mathrm{m}$ ). For the 
considered SiC-100 ceramic, the average failure stress in three-point flexure is equal to $370 \mathrm{MPa}$ (Table I) for samples with no macroscopic cracks and with the same size as those tested herein. For a mean toughness equal to $2.85 \mathrm{MPa} \sqrt{\mathrm{m}}$ [see Eqn. (11)], a value of $Y \approx 2$ is obtained.

For samples with no macroscopic cracks, there are two uncorrelated sources of scatter, namely the flaw size distribution (described by a probability density function $h$ ) and that corresponding to the toughness distribution [Eqn. (10)]. The failure probability $P_{\mathrm{F} 0}$ of a representative domain $\Omega_{0}$ can be written as

$$
P_{\mathrm{F} 0}=\int_{\mathcal{D}_{c}} g\left(K_{c}\right) h(a) \mathrm{d} K_{c} \mathrm{~d} a,
$$

where $\mathcal{D}_{c}$ is the set of critical defects (i.e., $Y \sigma^{\star} \sqrt{a} \geq K_{c}$ ) and $g$ the probability density function associated to $G$ (i.e., $g\left(K_{c}\right)=\mathrm{d} G / \mathrm{d} K_{c}$ ). Following the hypothesis made by Jayatilaka and Trustrum [30], the flaw size distribution $h$ is approximated by a power law function for large sizes (i.e., the weakest links)

$$
h(a) \approx \frac{\kappa(p-1)}{a_{0}}\left(\frac{a}{a_{0}}\right)^{-p},
$$

where $p, \kappa$ and $a_{0}$ are material-dependent parameters. Since the flaw distribution is only described for large sizes [Eqn. (15)], the integration of Eqn. is first performed with respect to the flaw size $a$, and then the toughness $K_{c}$ so that a first order solution is given by

$$
P_{\mathrm{F} 0} \approx \kappa \Gamma\left[\frac{n-2(p-1)}{n}\right]\left(\frac{\left\langle\sigma^{\star}\right\rangle}{S_{0}}\right)^{2(p-1)},
$$

where $Y S_{0} \sqrt{a_{0}}=K_{0}$ is the scale parameter relative to a reference toughness $K_{0}$ [Eqn. (10)] and defect size $a_{0}$ [Eqn. (15)], $\langle\bullet\rangle$ the Macauley brackets (i.e., the positive part of $\bullet$ ). Within the framework of the weakest link statistics [31], the failure probability $P_{\mathrm{F}}$ of a domain $\Omega$ can be expressed as a 
function of $P_{\mathrm{F} 0}$

$$
P_{\mathrm{F}}=1-\exp \left[-\lambda_{0} \int_{\Omega} \ln \left\{1-P_{\mathrm{F} 0}(\mathbf{x})\right\} \mathrm{d} \mathbf{x}\right],
$$

where $1 / \lambda_{0}$ is the volume of the domain $\Omega_{0}$. When combined with Eqn. (17), Eqn. (16) corresponds to a Weibull law [23] in terms of strength, where the Weibull modulus $m$ is equal to $2(p-1)$

$$
P_{\mathrm{F}} \approx 1-\exp \left[-\lambda_{0} \kappa \Gamma\left[1-\frac{m}{n}\right] \int_{\Omega}\left(\frac{\left\langle\sigma^{\star}(\mathbf{x})\right\rangle}{S_{0}}\right)^{m} \mathrm{~d} \mathbf{x}\right] .
$$

Equation (18) allows one to relate the classical Weibull parameters (i.e., for the strength distribution) to the flaw size distribution [Eqn. (15)] and that in toughness [Eqn. (10)]. When $m<n$ (i.e., the scatter in failure stress is more important than that in toughness), Eqns. (16) and (18) show that the scatter in terms of failure stress is dominated by that relative to the defect size distribution. The toughness scatter induces corrections by the presence of the $\Gamma$ function, which is defined as long as $n-m>0$.

The mechanical properties of SiC-100 ceramics are reported in Table I. The presence of sintering flaws induces a low average failure strength and a low Weibull modulus $m$. Consequently, the case $m<n$ applies and for the SiC-100 ceramic studied herein, the scatter in strength is dominated by that associated with the flaw size distribution of sintering defects.

\section{Summary}

An experimental procedure was developed to analyze the macroscopic toughness of a brittle material. A precracking set-up was designed to allow for optical observations during the experiment so that the onset and arrest of 
cracking can be monitored by using digital image correlation. The latter is the only means, in the present case, to accurately determine the load level at propagation inception thanks to the sub-pixel resolution of the technique. Coupled with a long-distance microscope, the resolution in displacement is of the order of $60 \mathrm{~nm}$ for an 8-bit CCD camera. Based on an FFT correlation algorithm, the computation time is less than one minute on a standard PC, thereby enabling for quasi-real time evaluations of displacement fields.

Crack detection, as well as crack propagation and location are also made possible. By using the proposed detection criterion, the crack location can be determined within a range of $30 \mu \mathrm{m}$ when used in the analysis of the toughness of a silicon carbide ceramic for which it can be evaluated with an accuracy of $3 \times 10^{-2} \mathrm{MPa} \sqrt{\mathrm{m}}$. This resolution allows us to conclude that the macroscopic toughness distribution is scattered with a Weibull modulus at least equal to 24 .

By using the macroscopic toughness distribution, and assuming that it is representative of the scatter at the scale of the defects leading to the failure of $\mathrm{SiC}$ ceramics, it is shown that the scatter in failure stress is dominated by that of the defect size distribution as opposed to that of the toughness because the Weibull modulus of the toughness distribution is greater than that of the failure stresses. This analysis also shows that, in the presence of a double source of scatter (namely, defect size and toughness distributions), the only knowledge of the strength Weibull parameters gives statistical indications on the most scattered of the two populations. This first analysis may be completed by other micro/macro toughness transitions (see, e.g., Refs. [29, 32]) to account for toughness scatter at the scale of the defects leading to the failure. 


\section{Acknowledgements}

This work was funded by DGA through a collaboration within the network

'Pôle Francilien de Dynamique' and by CNRS in a project entitled "Analyses multi-échelles de champs de déformation par traitement d'image : vers l'identification de champs de propriétés mécaniques."

\section{References}

1. Lemaitre, P., and R. Piller: 1988, 'Comparison of the Fracture Toughness of Alumina Measured by Three Different Methods,' J. Mat. Sci. Let. Vol. 7, pp. 772-774.

2. Sglavo, V.M., P. Bosetti, E. Trentini, and M. Ceschini: 1999, 'Sandwiched-Beam Procedure for Precracking Brittle Materials,' J. Am. Ceram. Soc. Vol. 82 no. 8, pp. 2269-2272.

3. Standard Test Method for Plane-Strain Fracture Toughness of Metallic Materials, ASTM Designation E 399-90, in: 1991 Annual Book of ASTM Standards, ASTM, Philadelphia (USA), 1991, pp. 412-442.

4. Lawn, B.R., Fracture of Brittle Solids, Cambridge University Press, Cambridge (UK), 1993.

5. VAMAS Round Robin on Fracture Toughness Measurement of Ceramic Matrix Composites, Japan Fine Ceramics Center, 1997.

6. Buresch, F.E., Fracture toughness testing of alumina, in: S.W. Freiman, eds., Fracture Mechanics Applied to Brittle Materials, ASTM, Philadelphia (USA), 1979, pp. 151-165.

7. Nose, T., and T. Fujii: 1988, 'Evaluation of Fracture Toughness for Ceramic Materials by a Single-Edge-Precracked-Beam Method,' J. Am. Ceram. Soc. Vol. 71 no. 5, pp. 328-333. 
8. Marshall, D.B., J.J. Ratto, and F.F. Lange: 1991, 'Enhanced Fracture Toughness in Layered Microcomposites of $\mathrm{Ce}-\mathrm{ZrO}_{2}$ and $\mathrm{Al}_{2} \mathrm{O}_{3}$, J. Am. Ceram. Soc. Vol. 74 no. 12, pp. 2979-2987.

9. Pancheri, P., P. Bosetti, R. Dal Maschio, and V.M. Sglavo: 1998, 'Production of Sharp Cracks in Ceramic Materials by Three-Point Bending of Sandwiched Specimens,' Eng. Fract. Mech. Vol. 59 no. 4, pp. 447-456.

10. Rastogi, P.K.: Photomechanics, Springer, Berlin (Germany), 2000.

11. Dawicke, D.S., and M.S. Sutton: 1994, 'CTOA and Crack-Tunnelling Measurements in Thin Sheet 2024-T3 Aluminum Alloy,' Exp. Mech. Vol. 34, pp. 357-368.

12. Sutton, M.A., S.R. McNeill, J.D. Helm, and Y.J. Chao, Advances in Two-Dimensional and Three-Dimensional Computer Vision, in: P.K. Rastogi, eds., Photomechanics, Springer, Berlin (Germany), 2000, pp. 323-372.

13. Srawley, J.E.: 1976, 'Wide Range of Stress Intensity Factor Expression for ASTM E399 Standard Fracture Toughness Specimens,' Int. J. Fract. Vol. 12, pp. 475-476.

14. Sutton, M.A., W.J. Wolters, W.H. Peters, W.F. Ranson, and S.R. McNeill: 1983, 'Determination of Displacements Using an Improved Digital Correlation Method,' Im. Vis. Comp. Vol. 1 no. 3, pp. 133-139.

15. Chu, T.C., W.F. Ranson, M.A. Sutton, and W.H. Petters: 1985, 'Applications of DigitalImage-Correlation Techniques to Experimental Mechanics,' Exp. Mech. Vol. 3 no. 25, pp. 232-244.

16. Chen, D.J., F.P. Chiang, Y.S. Tan, and H.S. Don: 1993, 'Digital Speckle-Displacement Measurement Using a Complex Spectrum Method,' Appl. Opt. Vol. 32, pp. 1839-1849.

17. Berthaud, Y., J. Scholz, and J. Thesing, Méthodes optiques et acoustiques de mesures des caractéristiques mécaniques, Proceedings of Colloque national MECAMAT 'Mécanismes et mécanique des grandes déformations,' 1996, pp. 77-80.

18. Chiang, F.P., Q. Wang, and F. Lehman, New Developments in Full-Field Strain Measurements Using Speckles, in: Non-Traditional Methods of Sensing Stress, Strain and Damage in Materials and Structures, ASTM, Philadelphia (USA), 1997, pp. 156-169.

19. Périé, J.N., S. Calloch, C. Cluzel, and F. Hild: 2002, 'Analysis of a Multiaxial Test on a C/C Composite by Using Digital Image Correlation and a Damage Model,' Exp. Mech. Vol. 42 no. 3, pp. 318-328. 
20. Hild, F., B. Raka, M. Baudequin, S. Roux, and F. Cantelaube: 2002, 'Multi-Scale Displacement Field Measurements of Compressed Mineral Wool Samples by Digital Image Correlation,' Appl. Optics IP Vol. 41 no. 32, pp. 6815-6828.

21. Riou, P.: Contribution à l'étude de l'endommagement du carbure de silicium lors d'un impact de basse énergie : application aux blindages, $\mathrm{PhD}$ thesis, École Nationale Supérieure des Mines de Paris, 1996.

22. Weibull, W.: 1951, 'A Statistical Distribution Function of Wide Applicability,' ASME J. Appl. Mech. Vol. 18 no. 3, pp. 293-297.

23. Weibull, W.: A Statistical Theory of the Strength of Materials, Roy. Swed. Inst. Eng. Res., no. 151, 1939.

24. Abramowitz, M., and I.A. Stegun: Handbook of Mathematical Functions, Dover Publications, Inc., New York (USA), 1965.

25. Merkel, I., and U. Messerschmidt: 1992, 'Fracture Toughness of Sintered SiC Ceramics: a Comparison Between Different Methods.,' Mat. Sci. Eng. Vol. A151, pp. 131-135.

26. Bouchaud, J.-P., E. Bouchaud, G. Lapasset, and J. Planés: 1993, 'Models of Fractal Cracks,' Phys. Rev. Lett. Vol. 71 pp. 2240-2243.

27. Perrin, G., and J.R. Rice: 1994, 'Disordering of a Dynamic Planar Crack Front in a Model Elastic Medium of Randomly Variable Toughness,' J. Mech. Phys. Solids Vol. 42 pp. 1047-1064.

28. Schmittbuhl, J., and K.J. Måløy: 1997, 'Direct Observation of a Self-Affine Crack Propagation,' Phys. Rev. Lett. Vol. 78 pp. 3888-3891.

29. Roux, S., D. Vandembroucq, and F. Hild: 2003, 'Effective Toughness of Heterogeneous Brittle Materials,' Eur. J. Mech. A/Solids Vol. 22 pp. 743-749.

30. Jayatilaka, A. de S., and K. Trustrum: 1977, 'Statistical Approach to Brittle Fracture,' J. Mater. Sci. Vol. 12, pp. 1426-1430.

31. Freudenthal, A.M., Statistical Approach to Brittle Fracture, in: H. Liebowitz, eds., Fracture, Academic Press, New York (USA), 1968, pp. 591-619.

32. Charles, Y., and F. Hild: 2002, 'Crack Arrest in ceramic/steel assemblies,' Int. J. Fract. Vol. 15 no. 3, pp. 251-272.

33. Denoual, C., and P. Riou, Comportement à l'impact de céramiques techniques pour blindages légers, CREA Report no. 95 R 005, Arcueil, France, 1995. 


\section{List of Tables}

I Mechanical properties of a SiC-100 ceramic (after Denoual and Riou [33]). 
Table I. Mechanical properties of a SiC-100

ceramic (after Denoual and Riou [33]).

\begin{tabular}{|l|c|}
\hline Young's modulus E (GPa) & 410 \\
\hline Poisson's ratio v & 0.15 \\
\hline Density & 3.15 \\
\hline Porosity & $1.8 \%$ \\
\hline Weibull modulus $m$ & 9.6 \\
\hline Mean strength (MPa) & 360 \\
\hline Effective volume (mm ${ }^{3}$ ) & 1.25 \\
\hline Number of samples & 65 \\
\hline Type of test & 3-point flexure \\
\hline
\end{tabular}

\section{Forquin et al.}




\section{List of Figures}

1 a-Schematic and main dimensions of a sandwiched-beam geometry. b-Average stress fields obtained by FE simulations when $f=0.3, F=2000 \mathrm{~N}, \alpha=0.4$ for a magnified deformed shape $\left(b_{A}=9 \mathrm{~mm}, b_{B}=9 \mathrm{~mm}, b_{N}=3 \mathrm{~mm}, w_{A}=5.5 \mathrm{~mm}\right.$, $\left.w_{B}=7 \mathrm{~mm}, w_{N}=5 \mathrm{~mm}, E_{A}=E_{B}=210 \mathrm{GPa}, E_{N}=410 \mathrm{GPa}\right) .27$

2 Stress intensity factor vs. dimensionless crack length for different configurations. The FE analyses (FEA) use different friction coefficients $f$ of the surfaces between the beams. The vertical dashed lines depict the range of notch sizes chosen in the present study.

3 Set-up for a sandwiched-beam experiment to precrack ceramics. For the sake of clarity, the right sliding block has been removed. The exploded view with no sliding blocks shows the geometric details of the support arm.

4 Micrograph of a typical sintering defect (dashed circle) in a SiC-100 ceramic.

5 a-Load $P$ vs. time $t$ for a ceramic sample $\left(r_{0}=3.6, \alpha_{0}=\right.$ $0.41)$. b-Picture taken at the onset of crack propagation $(P=$ $1050 \mathrm{~N})$. No crack is visible, even at high magnification.

6 Displacement contours of the horizontal displacement $u_{1}$ measured by digital image correlation (ZOI size: $64 \times 64$ pixels, ZOI shift: 16 pixels) when $P=1050 \mathrm{~N}$ in an SB test $\left(r_{0}=\right.$ 3.6). The crack is located inside the dashed circle. 
7 Contours of the horizontal displacement $u_{1}$ measured by digital image correlation (ZOI size: $32 \times 32$ pixels, ZOI shift: 16 pixels) for two different displacement ranges $(P=1200 \mathrm{~N})$ in an SB test $\left(r_{0}=3.6\right)$ : a- 0.1 pixel $\longleftrightarrow 0.185 \mu \mathrm{m}, \mathrm{b}-0.4$ pixel $\longleftrightarrow 0.74 \mu \mathrm{m}$

8 Measured vs. prescribed displacements $u_{1}$ for different sizes of ZOIs. The ZOI shift is equal to the length of the ZOI.

9 a-Contours of the horizontal displacement $u_{1}$ measured by digital image correlation (ZOI size: $32 \times 32$ pixels, ZOI shift: 16 pixels $)$ in an SENB test $\left(P=31.1 \mathrm{~N}, r_{0}=3.6\right)$. b-FE simulation of the horizontal displacement for the same crack size and load level (1 pixel $\longleftrightarrow 1.85 \mu \mathrm{m})$.

10 Contours of the horizontal displacement $u_{1}$ measured by digital image correlation (ZOI size: $32 \times 32$ pixels, ZOI shift: 16 pixels) when: a-the crack has stopped in the SB experiment $(P=1200 \mathrm{~N})$, b-prior to failure during the three-point flexure experiment $(P=31.1 \mathrm{~N})$.

11 a-Contours of the horizontal displacement $u_{1}$ measured by digital image correlation (ZOI size: $128 \times 128$ pixels, ZOI shift: 32 pixels) for a higher range. The position of the crack tip was deduced from the analysis of Fig. 10. b-COD $\llbracket u_{1} \rrbracket$ obtained by DIC and FE analysis of an SENB test $(P=31.1 \mathrm{~N}) .37$

12 a-Precrack size $\left(a / w_{N}=0.646\right)$ obtained from the contours of the horizontal displacement $u_{1}$ measured by digital image correlation (ZOI size: $32 \times 32$ pixels, ZOI shift: 16 pixels). b-Post-mortem evaluation of the precrack size $\left(a / w_{N}=0.651\right) .38$ 
13 Weibull plot of the toughness distribution and best fit for $n=$ 24 and $K_{0}=2.9 \mathrm{MPa} \sqrt{\mathrm{m}}$. 

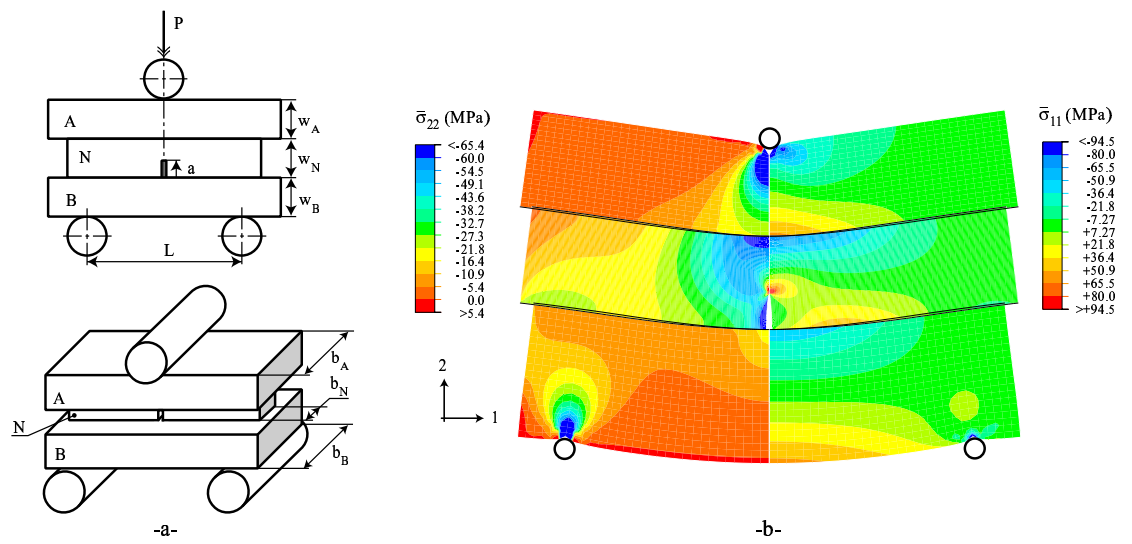

Figure 1. a-Schematic and main dimensions of a sandwiched-beam geometry. b-Average stress fields obtained by FE simulations when $f=0.3, F=2000 \mathrm{~N}, \alpha=0.4$ for a magnified deformed shape $\left(b_{A}=9 \mathrm{~mm}, b_{B}=9 \mathrm{~mm}, b_{N}=3 \mathrm{~mm}, w_{A}=5.5 \mathrm{~mm}, w_{B}=7 \mathrm{~mm}, w_{N}=5 \mathrm{~mm}\right.$, $\left.E_{A}=E_{B}=210 \mathrm{GPa}, E_{N}=410 \mathrm{GPa}\right)$.

Forquin et al. 


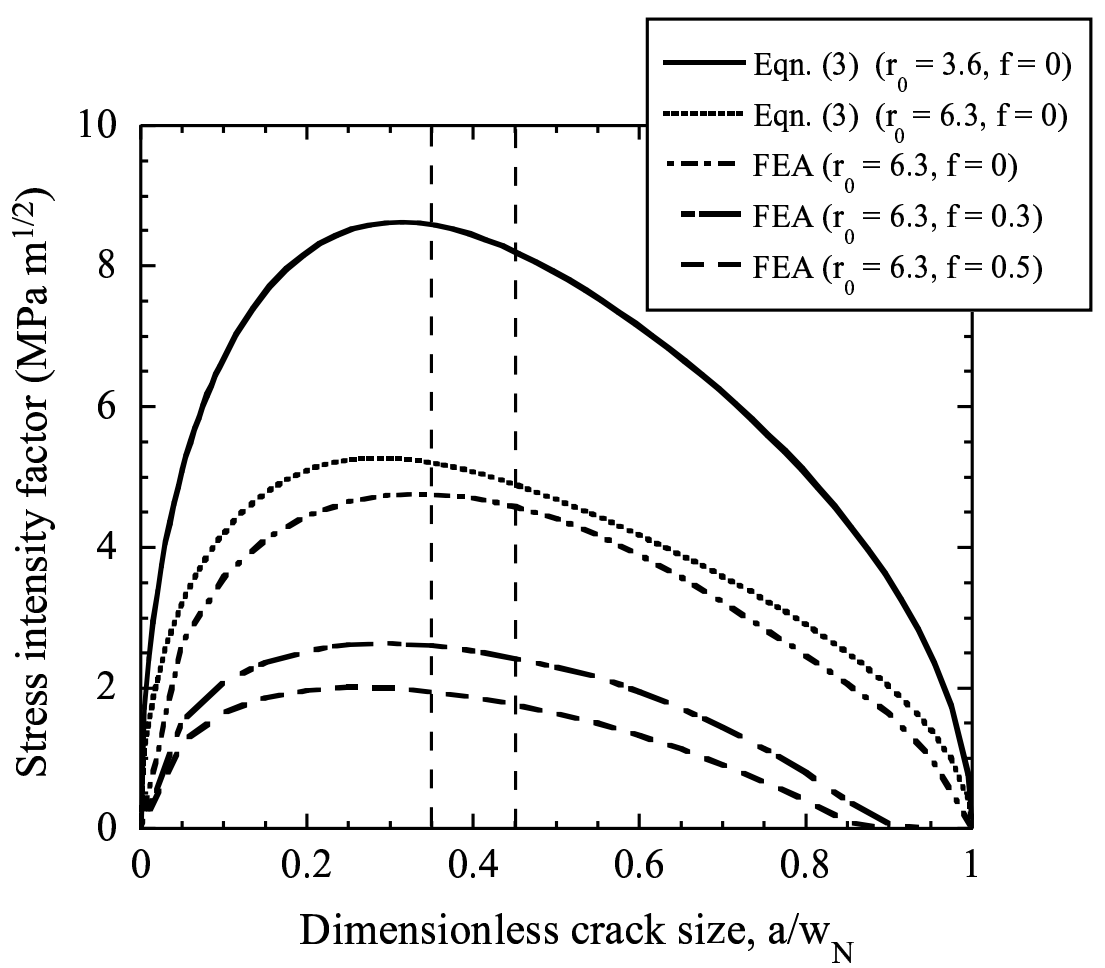

Figure 2. Stress intensity factor vs. dimensionless crack length for different configurations. The FE analyses (FEA) use different friction coefficients $f$ of the surfaces between the beams. The vertical dashed lines depict the range of notch sizes chosen in the present study.

Forquin et al. 


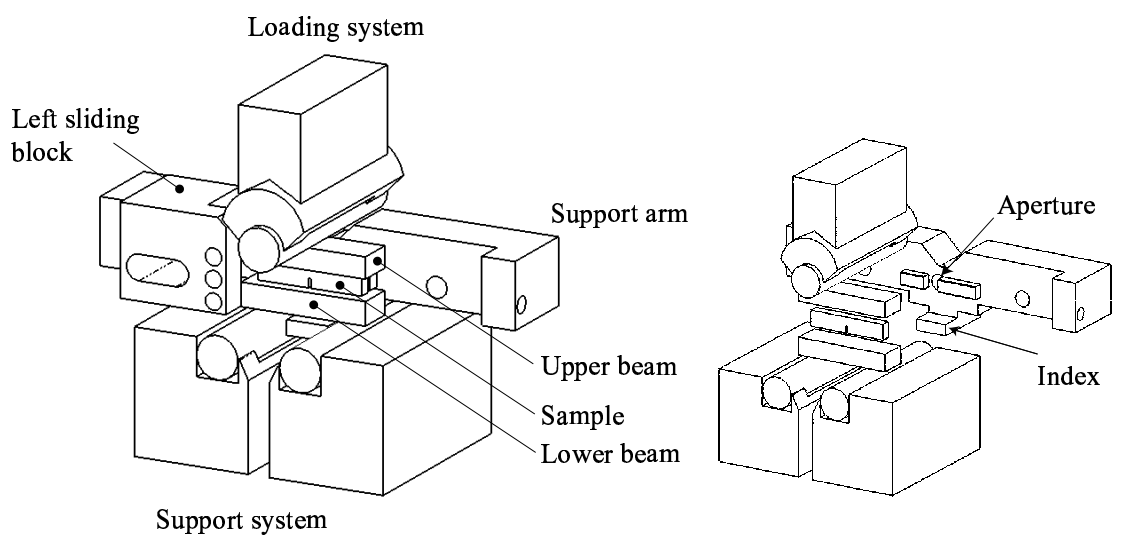

Figure 3. Set-up for a sandwiched-beam experiment to precrack ceramics. For the sake of clarity, the right sliding block has been removed. The exploded view with no sliding blocks shows the geometric details of the support arm.

Forquin et al. 


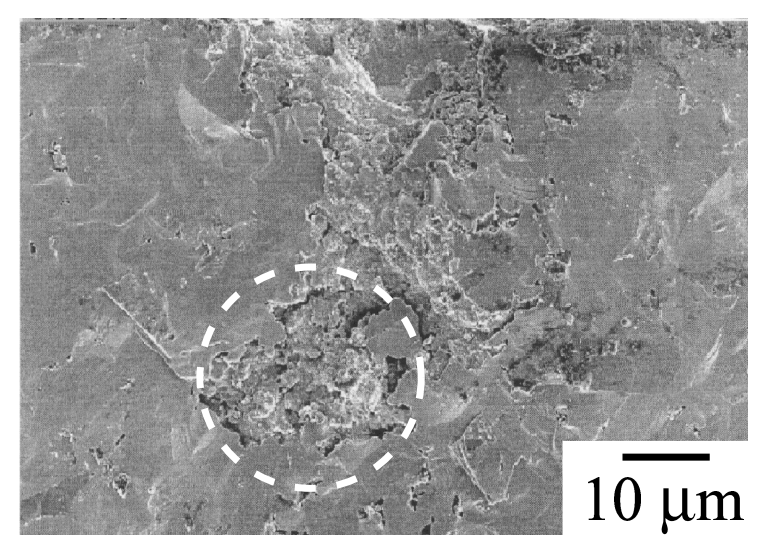

Figure 4. Micrograph of a typical sintering defect (dashed circle) in a SiC-100 ceramic.

Forquin et al. 


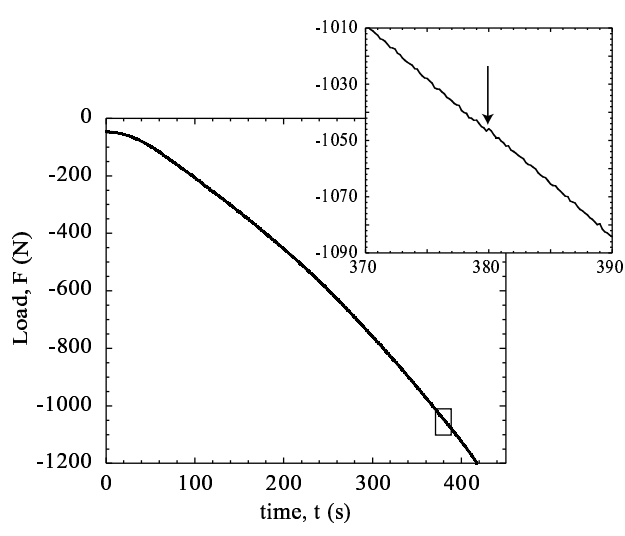

-a-

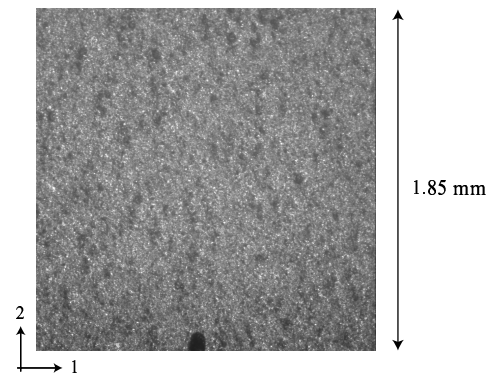

-b-

Figure 5. a-Load $P$ vs. time $t$ for a ceramic sample $\left(r_{0}=3.6, \alpha_{0}=0.41\right)$. b-Picture taken at the onset of crack propagation $(P=1050 \mathrm{~N})$. No crack is visible, even at high magnification.

\section{Forquin et al.}




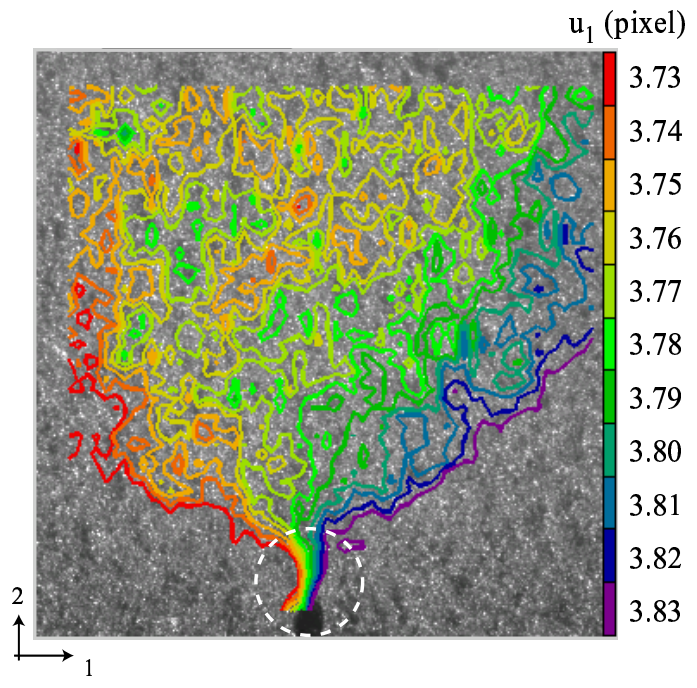

Figure 6. Displacement contours of the horizontal displacement $u_{1}$ measured by digital image correlation (ZOI size: $64 \times 64$ pixels, ZOI shift: 16 pixels) when $P=1050 \mathrm{~N}$ in an SB test $\left(r_{0}=3.6\right)$. The crack is located inside the dashed circle.

\section{Forquin et al.}



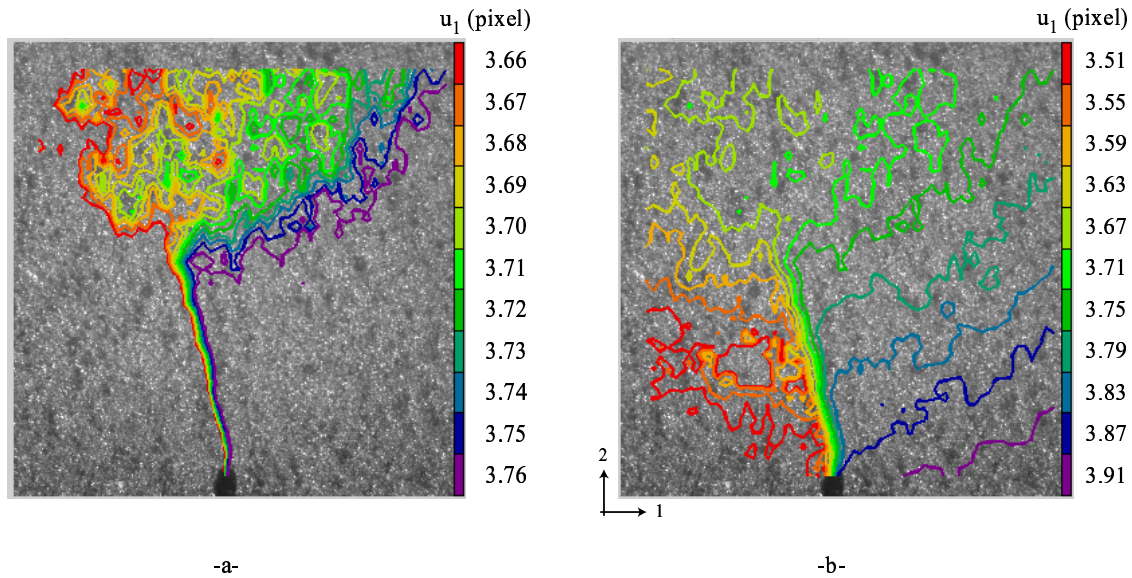

Figure 7. Contours of the horizontal displacement $u_{1}$ measured by digital image correlation (ZOI size: $32 \times 32$ pixels, ZOI shift: 16 pixels) for two different displacement ranges $(P=1200 \mathrm{~N})$ in an SB test $\left(r_{0}=3.6\right)$ : a- 0.1 pixel $\longleftrightarrow 0.185 \mu \mathrm{m}, \mathrm{b}-0.4$ pixel $\longleftrightarrow 0.74 \mu \mathrm{m}$.

Forquin et al. 


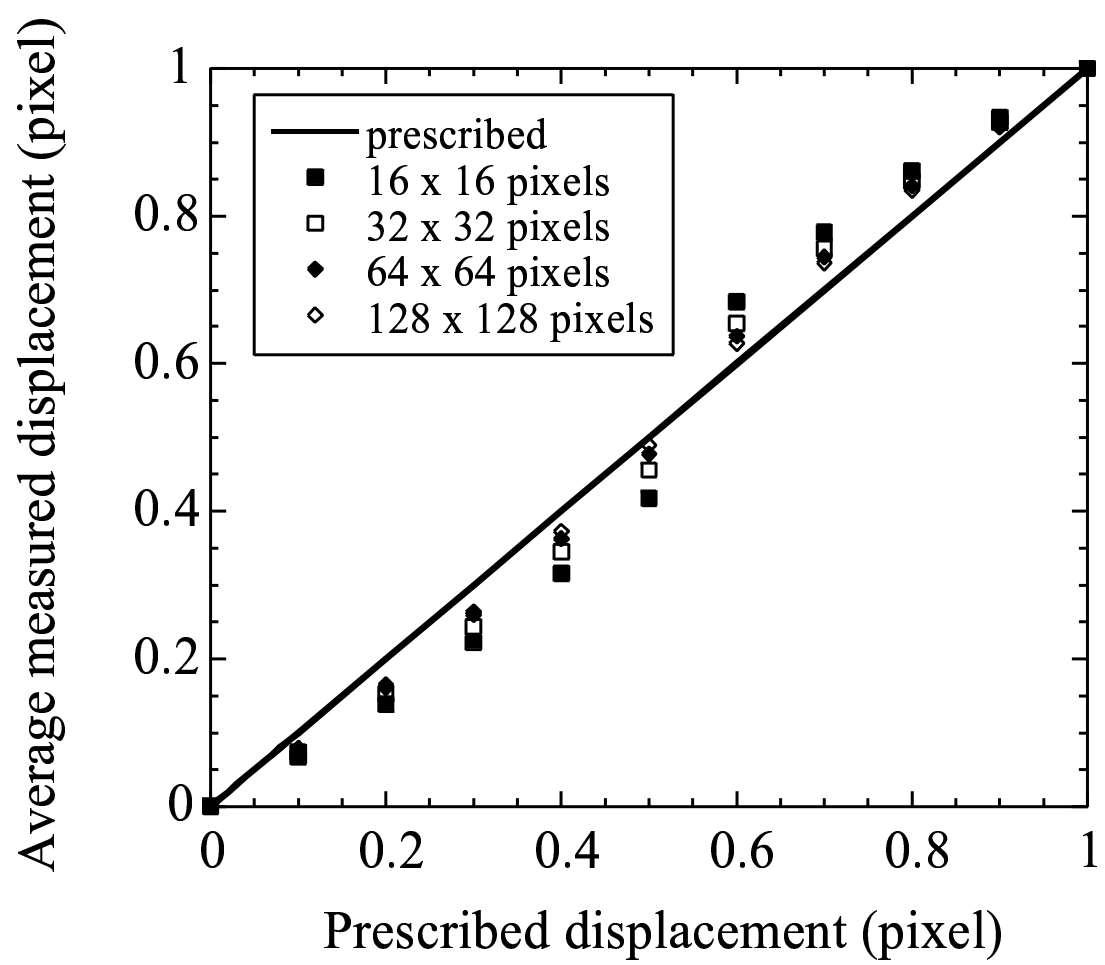

Figure 8. Measured vs. prescribed displacements $u_{1}$ for different sizes of ZOIs. The ZOI shift is equal to the length of the ZOI.

Forquin et al. 

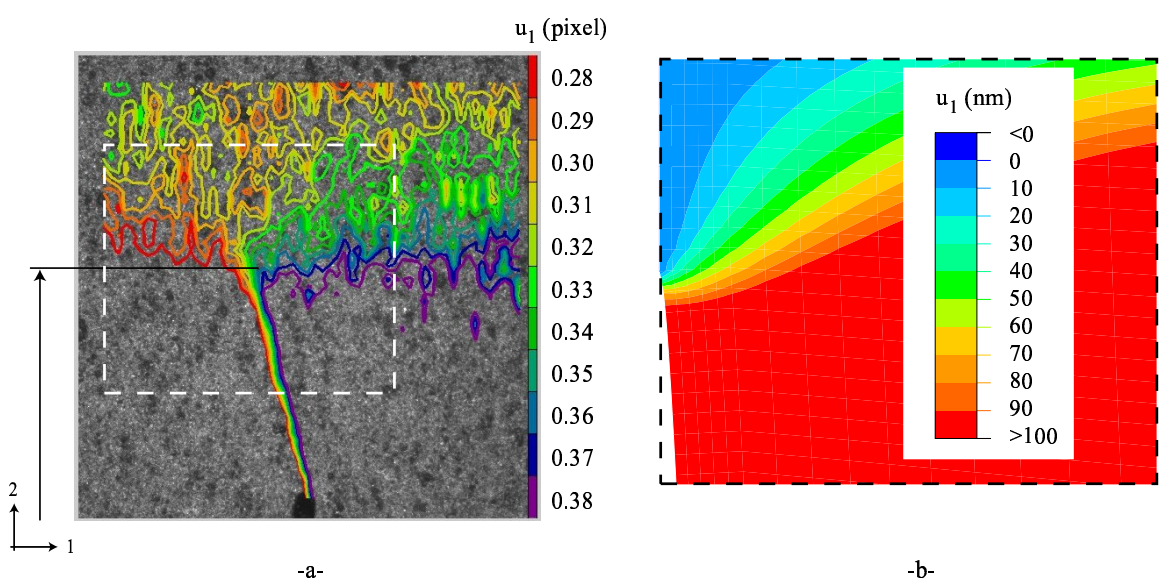

$-b-$

Figure 9. a-Contours of the horizontal displacement $u_{1}$ measured by digital image correlation (ZOI size: $32 \times 32$ pixels, ZOI shift: 16 pixels) in an SENB test $\left(P=31.1 \mathrm{~N}, r_{0}=3.6\right)$. b-FE simulation of the horizontal displacement for the same crack size and load level (1 pixel $\longleftrightarrow 1.85 \mu \mathrm{m})$.

Forquin et al. 


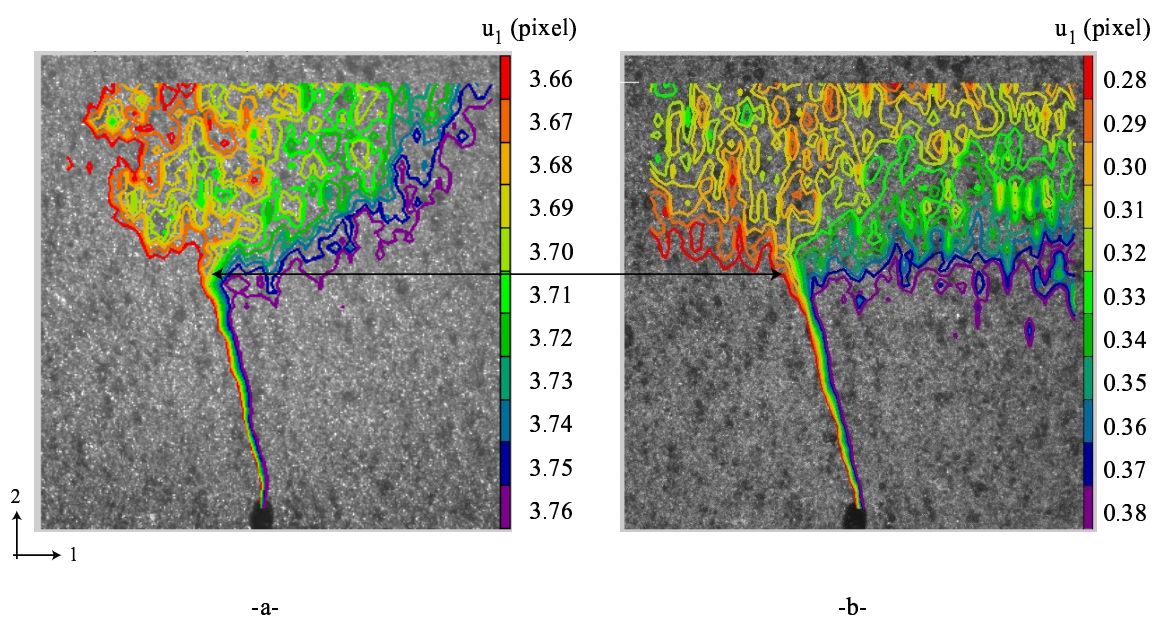

Figure 10. Contours of the horizontal displacement $u_{1}$ measured by digital image correlation (ZOI size: $32 \times 32$ pixels, ZOI shift: 16 pixels) when: a-the crack has stopped in the SB experiment $(P=1200 \mathrm{~N})$, b-prior to failure during the three-point flexure experiment $(P=31.1 \mathrm{~N})$.

Forquin et al. 

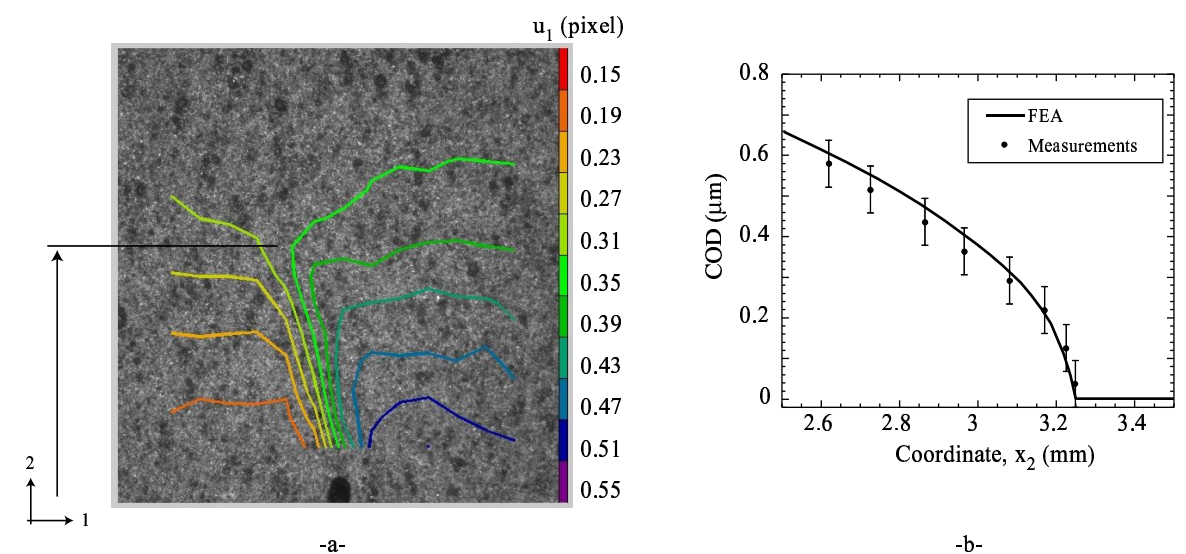

Figure 11. a-Contours of the horizontal displacement $u_{1}$ measured by digital image correlation (ZOI size: $128 \times 128$ pixels, ZOI shift: 32 pixels) for a higher range. The position of the crack tip was deduced from the analysis of Fig. 10. b-COD $\llbracket u_{1} \rrbracket$ obtained by DIC and FE analysis of an SENB test $(P=31.1 \mathrm{~N})$.

Forquin et al. 


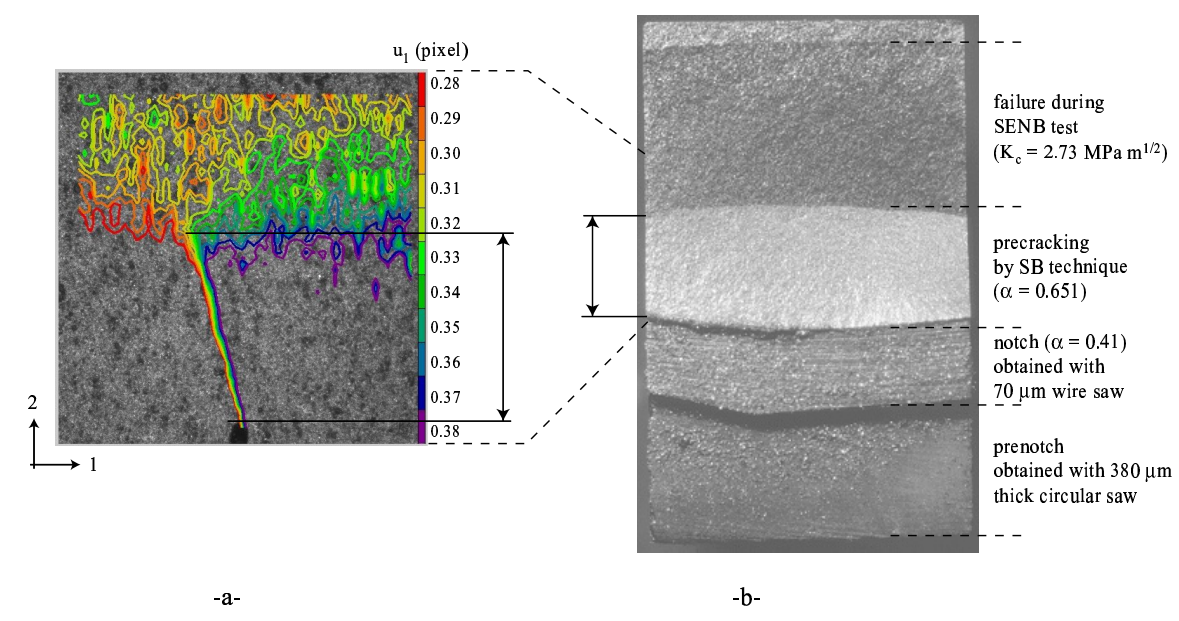

Figure 12. a-Precrack size $\left(a / w_{N}=0.646\right)$ obtained from the contours of the horizontal displacement $u_{1}$ measured by digital image correlation (ZOI size: $32 \times 32$ pixels, ZOI shift: 16 pixels). b-Post-mortem evaluation of the precrack size $\left(a / w_{N}=0.651\right)$.

\section{Forquin et al.}




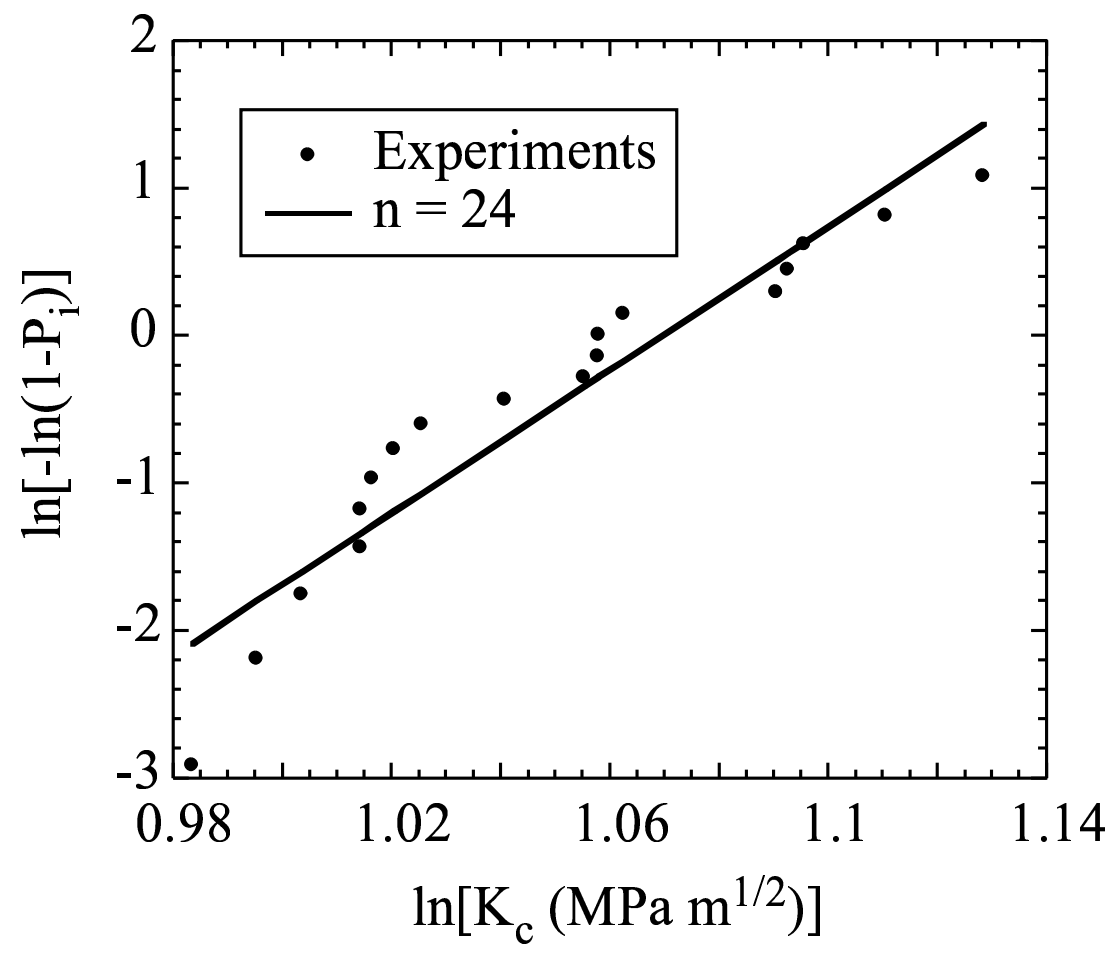

Figure 13. Weibull plot of the toughness distribution and best fit for $n=24$ and $K_{0}=2.9 \mathrm{MPa} \sqrt{\mathrm{m}}$.

Forquin et al. 
Address for Offprints:

François HILD (corresponding author)

LMT-Cachan

ENS de Cachan / CNRS-UMR 8535 / Université Paris 6

61 avenue du Président Wilson, F-94235 Cachan Cedex, France. 